\title{
Growth of the pulmonary artery after neonatal balloon dilatation of the right ventricular outflow tract in an infant with the tetralogy of Fallot and atrioventricular septal defect
}

\author{
J M PARSONS, E J LADUSANS, S A QURESHI \\ From the Department of Paediatric Cardiology, Guy's Hospital, London
}

SUMMARY A two week old girl with tetralogy of Fallot and atrioventricular septal defect underwent palliation, for severe hypoxaemia, by balloon dilatation to the right ventricular outflow tract. This procedure was repeated once over the next eight months without complications. Serial right ventricular angiograms showed growth of the hypoplastic pulmonary ring ("annulus"), trunk, and arteries.

Balloon dilatation is an alternative palliative procedure for patients with the tetralogy of Fallot which may promote growth of the pulmonary ring, trunk, and arteries.

Surgical systemic to pulmonary artery shunts for tetralogy of Fallot have been shown to produce growth of pulmonary ring, trunk, and arteries. ${ }^{1-3}$ Shunt surgery, however, is not without risk and complications such as shunt occlusion, kinking of the pulmonary arteries, and pulmonary hypertension ${ }^{46}$ can occur. The operative mortality varies from $0 \%$ to $13 \%{ }^{47}$ A recent preliminary study has shown encouraging results of balloon dilatation of the right ventricular outflow tract as an alternative palliative procedure ${ }^{8}$; however, objective evidence of pulmonary artery growth was not evaluated.

We report a case of tetralogy of Fallot with atrioventricular septal defect in which growth of associated hypoplastic pulmonary ring, trunk, and arteries was shown after balloon dilatation of the right ventricular outflow tract.

\section{Case report}

A day old girl, birth weight $2 \cdot 4 \mathrm{~kg}$, presented with severe central cyanosis. Physical examination showed features of trisomy 21 syndrome and an ejection systolic murmur along the left sternal border. A chest $x$ ray showed an enlarged heart with oligaemic lung fields. The electrocardiogram showed sinus rhythm with a superior QRS axis. Echocardiography showed an atrioventricular septal

Requests for reprints to Dr J M Parsons, Department of Paediatric Cardiology, Guy's Hospital, St Thomas Street, London SE1 9RT. defect and tetralogy of Fallot with severe hypoplasia of the pulmonary ring, trunk, and arteries. Treatment with intravenous prostaglandin $\mathrm{E}_{2}$ was started. Because she was still dependent upon the prostaglandin $\mathrm{E}_{2}$ after two weeks, palliation with balloon dilatation of the right ventricular outflow tract was performed.

Cardiac catheterisation was performed under general anaesthesia with $100 \%$ oxygen. Right ventricular angiograms in anteroposterior and lateral projections (fig $1 \mathrm{a}$ and $\mathrm{b}$ ) showed severe narrowing of the infundibulum and hypoplasia of the pulmonary ring and trunk and small pulmonary arteries (table 1). The diameter of the pulmonary ring was $4.2 \mathrm{~mm}$ and several dilatations were initially performed with a Schneider $6 \mathrm{~mm}$ diameter balloon catheter. This procedure was then repeated with a Schneider $8 \mathrm{~mm}$ diameter balloon catheter. There were no complications during or after the procedure. Oxygen saturation in the femoral artery increased from $84 \%$ at the start of the procedure to $92 \%$ at the end. Prostaglandin $\mathrm{E}_{2}$ was then stopped.

Nine weeks later she was readmitted because of hypercyanotic episodes. She was being treated with propranolol ( $3 \mathrm{mg} / \mathrm{kg} / 24$ hours). She had gained weight to $3.86 \mathrm{~kg}$. Haemoglobin was $177 \mathrm{~g} / 1$ and the haematocrit was 0.536 . Balloon dilatation was repeated. Right ventricular angiograms in both the anteroposterior and lateral projections showed that there had been an increase in size of the pulmonary ring (which now measured $6 \mathrm{~mm}$ ), the pulmonary 
Fig 1 (a) Right ventricular angiogram in anteroposterior projection obtained at time of first palliation showing hypoplasia of the pulmonary ring, trunk (single arrow), and arteries (double arrows). (b) Lateral projection of the same right ventricular angiogram.

Table 1 Angiographic measurements corrected for magnification

\begin{tabular}{|c|c|c|c|c|c|c|c|}
\hline \multirow[b]{2}{*}{ Catheter } & \multicolumn{7}{|c|}{ Dimensions ( $\mathrm{mm}$ ) } \\
\hline & $P R$ & $P T$ & $\begin{array}{l}R P A \\
(D)\end{array}$ & $\begin{array}{l}R P A \\
(P)\end{array}$ & $\begin{array}{l}L P A \\
\text { (D) }\end{array}$ & $\begin{array}{l}L P A \\
(P)\end{array}$ & $D s A o$ \\
\hline $\begin{array}{l}1 \\
2 \\
3\end{array}$ & $\begin{array}{l}4.2 \\
6.0 \\
6.7\end{array}$ & $\begin{array}{l}4.2 \\
4.0 \\
6.4\end{array}$ & $\begin{array}{l}3.2 \\
5.6 \\
8.9\end{array}$ & $\begin{array}{l}3.2 \\
4.8 \\
8 \cdot 1\end{array}$ & $\begin{array}{l}3.7 \\
4.0 \\
5.8\end{array}$ & $\begin{array}{l}3.7 \\
3.7 \\
6.2\end{array}$ & $\begin{array}{l}6.1 \\
6.0 \\
6.9\end{array}$ \\
\hline
\end{tabular}

PR, pulmonary ring; PT, pulmonary trunk; RPA, right pulmonary artery; LPA, left pulmonary artery; (D), distal; (P), proximal; DsAo, descending aorta.

trunk, and arteries (table 1). Several inflations were performed with $8 \mathrm{~mm}$ and $9 \mathrm{~mm}$ Schneider balloon catheters. Femoral arterial saturation increased from $56 \%$ to $73 \%$ while she was treated with $50 \%$ oxygen. Propranolol was then withdrawn.

Five months later she was readmitted with moderate central cyanosis. The haemoglobin was now $196 \mathrm{~g} / 1$ with a haematocrit of 0.644 . She had continued to grow and now weighed $5 \mathrm{~kg}$. Repeat cardiac catheterisation and angiocardiography of the right ventricle showed further growth of the pulmonary ring, trunk, and arteries (table 1). In addition, there was moderate supravalvar stenosis and the infundibulum also seemed less narrow (fig 2). She subsequently underwent a successful right modified Blalock-Taussig shunt procedure.

\section{ANGIOGRAPHIC MEASUREMENTS}

Most measurements were recorded from right ventricular angiograms in the anteroposterior projection, although in a few cases the lateral projection was used. Measurements were taken to the nearest $0.5 \mathrm{~mm}$ and then corrected for magnification. The

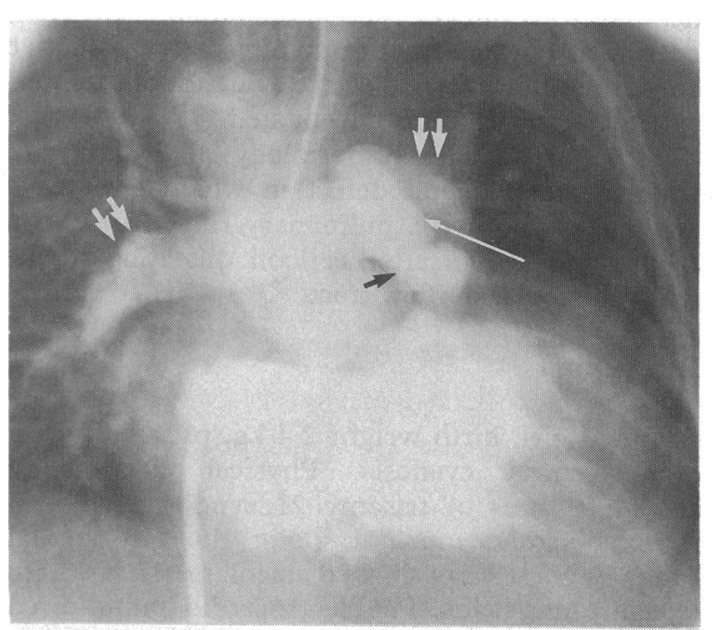

Fig 2 Right ventricular angiogram in anteroposterior projection obtained at third cardiac catheterisation. The pulmonary ring trunk (single white arrow) and arteries (double arrows) had increased in size. There was also evidence of supravalvar pulmonary stenosis (black arrow). 
Table 2 Angiographic measurements normalised by use of the ratio to the descending aorta

\begin{tabular}{lllll}
\hline Catheter & $P R$ & $P T$ & $R P A$ & $L P A$ \\
\hline 1 & 0.69 & 0.69 & 0.52 & 0.6 \\
2 & 1.0 & 0.67 & 0.93 & 0.67 \\
3 & 0.97 & 0.92 & 1.29 & 0.84 \\
\hline
\end{tabular}

PR, pulmonary ring; PT, pulmonary trunk; RPA, right pulmonary artery; LPA, left pulmonary artery; DsAo, descending aorta.

pulmonary ring and trunk were measured during early systole and again in mid-diastole and the average value was taken. The pulmonary artery was measured just distal to the bifurcation and just proximal to the origin of the first branch at end systole. The descending thoracic aorta was measured at the level of the diaphragm, also at end systole.

The dimensions of the pulmonary ring, trunk, and artery were then normalised by using their ratio with the descending thoracic aorta ${ }^{9}$ (table 2). We calculated predictive postoperative right ventricular/ left ventricular pressure ratios by the methods described by Blackstone and colleagues. ${ }^{10}$ Measurements taken from the first angiogram gave a predictive ratio of 0.63 for correction by a conduit or transannular patch and 0.82 for straightforward correction. The predictive ratios calculated from the final angiogram were 0.43 and 0.59 respectively.

\section{Discussion}

The mortality for primary correction of tetralogy of Fallot is between $1 \%$ and $5 \% .{ }^{11}$ Young age and small pulmonary arteries are important risk factors and many centres would perform an initial palliative procedure to encourage growth of the pulmonary arteries. ${ }^{12}$ Palliative operations including closed pulmonary valvotomy and infundibular resection (Brock's procedure) and systemic to pulmonary artery shunts have all been shown to promote growth of the pulmonary valve annulus and pulmonary arteries. ${ }^{1313}$ The subsequent need for a transannular patch is reduced and operative risks are decreased. These operations are, however, associated with serious complications and a considerable mortality.

Complications after closed pulmonary valvotomy and infundibular resection include heart failure and inadequate relief of symptoms requiring a second palliative procedure. The mortality is around $15 \%{ }^{13}$ Blalock-Taussig shunts are associated with early and late occlusion in approximately $10 \%, 4$ with a significantly higher rate of late occlusion occurring in children less than four weeks of age at the time of shunt insertion. ${ }^{7}$ The operative mortality varies between $0 \%$ and $8 \% .^{7414}$ Waterston shunts are associated with complications ${ }^{56}$ of pulmonary vascular disease and serious kinking, usually of the right pulmonary artery, in up to $16 \%$. The operative mortality is between $5 \%$ and $13 \%{ }^{7}{ }^{75}$ Since mortality for total correction of tetralogy of Fallot and atrioventricular septal defect is high (27\% hospital mortality ${ }^{11}$ ) the operation is usually delayed until the patient is older and this delay is dependent on successful long term palliation. In view of these problems balloon dilatation of the right ventricular outflow tract has been suggested as an alternative palliative procedure. ${ }^{8}$

In our patient balloon dilatation was an attractive palliative procedure because it could potentially delay the shunt operation until the patient was older and consequently increase the chance of the shunt remaining patent for longer. Dilatation gave adequate palliation for eight months but more importantly it resulted in the additional benefit of pulmonary artery growth with its associated advantages.

To examine pulmonary artery growth we used normalised measurements (growth of the descending aorta was assumed to be constant) by a method already used in infants and children. ${ }^{129}$ We found that over the study period the pulmonary ring, trunk, and arteries grew more rapidly than normal. Another method of indirectly assessing pulmonary artery growth is by using the calculations described by Blackstone to predict postoperative right ventricular/ left ventricular pressure ratios. ${ }^{10} \mathrm{~A}$ predicted ratio around 0.85 after correction without the use of a transannular patch or conduit is generally felt to be unacceptably high and indicates that a transannular patch or at least a conduit will be necessary. A ratio of 0.82 , obtained in our patient at the time of the first catheter, suggests a transannular patch would probably have been required if early corrective operation had been contemplated. At the time of the final catheter, however, this ratio had fallen to 0.59 , suggesting that a transannular patch is now less likely to be required at correction and this indirectly implies pulmonary artery enlargement.

In a report of a series of 24 balloon dilatations in infants with tetralogy of Fallot 21 were uncomplicated. ${ }^{8}$ The results were encouraging, with $73 \%$ of the patients successfully palliated for a mean period of 8.5 months. However, in this series the growth of the pulmonary arteries after balloon dilatation was not commented on. We believe that balloon dilatation of the right ventricular outflow tract is a safe, effective palliative procedure for the tetralogy of Fallot that may additionally promote growth of the pulmonary ring, trunk, and arteries. 


\section{References}

1 Gale AW, Arciniegas E, Green EW, Blackstone EH, Kirklin JW. Growth of the pulmonary annulus and pulmonary arteries after the Blalock-Taussig shunt. $J$ Thorac Cardiovasc Surg 1979;77:459-65.

2 Kirklin JW, Bargeron LM Jr, Pacifico AD. The enlargement of small pulmonary arteries by preliminary palliative operations. Circulation 1977;75:612-7.

3 Alfieri O, Blackstone EH, Parenzan L. Growth of the pulmonary annulus and pulmonary arteries after the Waterston anastomosis. $J$ Thorac Cardiovasc Surg 1979;78:440-4.

4 Kay PH, Capuani A, Franks R, Lincoln C. Experience with the modified Blalock-Taussig operation using polytetrafluoroethylene (Impra) grafts. Br Heart J 1983;49:359-63.

5 Newfield EA, Waldman JD, Paul MH, et al. Pulmonary vascular disease after systemic-pulmonary arterial shunt operations. Am J Cardiol 1977;39:715-21.

6 Gay WA, Ebert PA. Aorta to right pulmonary artery anastomosis causing obstruction of the right pulmonary artery: management during correction of tetralogy of Fallot. Ann Thorac Surg 1973;16:402-10.

7 Arciniegas E, Farooki ZQ, Hakimi M, Perry BL, Green EW. Classical shunting operations for congenital cyanotic heart defects. J Thorac Cardiovasc Surg 1982;84:88-96.

8 Qureshi SA, Kirk CR, Lamb RK, Amold R, Wilkinson
JL. Balloon dilatation of the pulmonary valve in the first year of life in patients with tetralogy of Fallot: a preliminary study. Br Heart J 1988;60:232-5.

9 McGoon DC, Baird DK, Davis GD. Surgical management of large bronchial collateral arteries with pulmonary stenosis or atresia. Circulation 1975; 52:109-18.

10 Blackstone EH, Kirklin JW, Bertranou EG, Labrosse CJ, Soto B, Bargeron LM Jr. Preoperative prediction from cineangiograms of postrepair right ventricular pressure in tetralogy of Fallot. $J$ Thorac Cardiovasc Surg 1979;78:542-52.

11 Kirklin JW, Barratt-Boyes BG. Cardiac surgery. New York: Wiley Medical, 1986:766-88.

12 Kirklin JW, Blackstone EH, Pacifico AD, Brown RN, Bargeron LM Jr. Routine primary repair vs two stage repair of tetralogy of Fallot. Circulation 1979;60: 373-86.

13 Brock RC. Late results of palliative operations for Fallot's tetralogy. J Thorac Cardiovasc Surg 1974; 67:511-8.

14 Guyton RA, Owens JE, Waumett JD, Dooley KJ, Hatcher CH, Williams WH. The Blalock-Taussig shunt, low risk, effective palliation and pulmonary artery growth. $J$ Thorac Cardiovasc Surg 1983;85: 917-22.

15 Parenzan L, Alfieri O, Vanini V, et al. Waterston anastomosis for initial palliation of tetralogy of Fallot. $J$ Thorac Cardiovasc Surg 1981;82:176-81. 